\title{
A desconstrução das narrativas e a reconstrução do currículo: a inclusão dos saberes matemáticos dos negros e dos índios brasileiros
}

\section{Narratives deconstruction and curriculum reconstruction: the inclusion of Brazilian indians' and black people's mathematical knowledge}

\author{
Wanderleya Gonçalves Costa ${ }^{1}$ \\ Vanisio Luiz Silva
}

\begin{abstract}
RESUMO
Neste artigo, problematizamos as narrativas da nação brasileira que mascaram a identidade múltipla do País e ressaltamos mecanismos de exclusão presentes nas escolas. Lembramos que o Brasil, devido à sua formação histórico-social, é multirracial e pluriétnico, mas a escola continua a desconsiderar essa realidade, o que tem contribuído para elevar os índices de evasão e repetência de crianças provenientes de alguns grupos socioculturais. Então, remetendo-nos à aprovação da Lei 11.645/08, que inclui no currículo oficial dos estabelecimentos de ensino básico das redes pública e privada a obrigatoriedade do estudo da história e culturas africana, afrobrasileira e indígena, encaminhamos nossas discussões para o ensino de Matemática. Nesse contexto, discorremos sobre algumas das formas por meio das quais as pesquisas em Etnomatemática podem contribuir para discutir e destacar, no espaço escolar, os conhecimentos que possuem essas matrizes culturais. A partir daí, apresentamos algumas reflexões suscitadas por pesquisas que temos realizado na região de Pirituba, no município de São Paulo, onde atua o segundo autor e junto aos índios A'uwe-xavante
\end{abstract}

1 Doutora em Educação pela USP. Professora da Universidade Federal de Mato Grosso.

2 Mestre em Educação pela USP. Professor da Rede de Ensino Municipal de São Paulo. 
do Mato Grosso, onde atua a primeira autora.

Palavras-chave: educação matemática; etnomatemática; identidade.

\begin{abstract}
In this article, narratives from the Brazilian nation are problematized, which disguise the country multiple identity and we emphasize mechanisms of exclusion present in schools. We remind that Brazil, because of its historical and social organization is multiracial and pluriethnical, but school continues to ignore this reality, which has contributed to raise the dropout and repetition rates of children from some socio-cultural groups. Then, concerning the 11.645/08 Law approval, which includes the compulsory study of the history and culture from Africans, Brazilian Africans and indigenous added in the official curriculum of private and public elementary schools, we guided our discussions for the teaching of Mathematics. In this context, talking about how research in Ethnomathematics can help enhancing, at school, the knowledge from those cultural matrix. From there, we present some thoughts raised by the research we have conducted in Pirituba, in Sao Paulo city, where the second author works, and close to the A'uwe-Xavante Indians of Mato Grosso state, the subject of doctoral research by the first author.
\end{abstract}

Keywords: mathematics education; ethnomathematics; identity.

\title{
Considerações primeiras
}

Neste texto, compartilhamos alguns elementos que têm estado presentes nas nossas reflexões sobre a inclusão dos saberes matemáticos dos negros e dos índios brasileiros no currículo da escola básica. Para tanto, inicialmente, problematizaremos os efeitos das narrativas e das contranarrativas nacionais no reconhecimento das especificidades dos povos e culturas negras e indígenas e da própria identidade do povo brasileiro. Ressaltaremos que, no contexto escolar, as narrativas históricas mais consolidadas se relacionam a uma identidade nacional excludente que, não raro, deixa de revelar os saberes e também as mazelas dos diferentes povos que constituem a população nacional.

Em seguida, destacaremos o papel que a Educação Matemática, por meio da Etnomatemática, tem assumido no sentido de discutir, propor mudanças e enfrentar os estereótipos a partir da qual negros e índios são representados 
como não criadores de conhecimentos matemáticos, ou como geradores de conhecimentos matemáticos de menor valor. Salientaremos que, a partir desse tipo de atuação, a Etnomatemática tem contribuído para a constituição de uma contranarrativa que assume o Brasil como um país plural e o ensino de matemática como área capaz de aliar-se à luta dos negros e dos índios em prol do respeito às suas histórias e culturas.

\section{As narrativas e as contranarrativas sobre o povo brasileiro}

O termo "povo brasileiro" nos remete à identidade de uma nação. Essa identidade está relacionada a representações e símbolos, entre os quais está a “narrativa de nação”. Uma narrativa de nação, explica Hall (2003, p. 52), constitui um conjunto de histórias, imagens, paisagens, cenários, acontecimentos históricos, símbolos nacionais e rituais que simbolizam ou representam as experiências, os sofrimentos, os triunfos e os desastres partilhados que conferem significado à nação. Enquanto membros de uma nação, nos vemos como sujeitos dessa narrativa e estabelecemos uma ligação entre as nossas vidas quotidianas e um destino nacional. Como membros de uma nação, as pessoas, sejam elas brancas, negras, índias ou mestiças, encontram o seu lugar nas narrativas nacionais. Mas, afirma Ramos Júnior (2008), nas narrativas de nação latino-americanas e caribenhas, permeia a ideia de se efetivar uma missão civilizadora que passa pela erradicação de povos negros, mestiços e indígenas, descritos como bárbaros, selvagens ou primitivos.

Em particular, a narrativa da nação brasileira, tal como foi constituída, serve, inclusive, para escamotear fatos, para obter/manter uma paz social por meio de uma adequação dos papéis distribuídos às minorias ${ }^{3}$ sociais ao longo da história. Entretanto, têm sido engendradas contranarrativas, isto é, narrativas outras, baseadas na crítica da representação negativizada que a narrativa da nação brasileira projeta sobre negros e índios. As contranarrativas se propõem a desestabilizar estereótipos, construindo sentidos e representações alternativas, redefinindo a identidade nacional. Elas salientam, por exemplo, que a miscigenação entre índios, brancos e negros brasileiros ocorreu de forma efetiva em nível biológico; mas em termos psicológicos, políticos, econômicos e sociais, isso não se deu em mesmo grau.

Nesse sentido, são ilustrativos os dados revelados pelo IPEA - Instituto de Pesquisas e Econômicas Aplicadas - que, ao comparar a desigualdade de renda entre as famílias negras e brancas do Brasil, informa-nos que, em 2008,

3 Minorias não em termos de número, mas sim de poder e representação. 
a população branca ainda vivia no país com mais que o dobro da renda disponível, em média, para a população negra. $\mathrm{O}$ instituto afirma ainda que a taxa de analfabetismo entre jovens negros é quase duas vezes superior à taxa entre brancos e que, no período compreendido entre 2001 e 2007 não houve alteração no quadro de oportunidades no mercado de trabalho para os negros - principal fonte de renda e de mobilidade social ascendente.

Por outro lado, o descaso para com os povos indígenas tem sido tão grande que não têm sido realizados pesquisas mais sistemáticas sobre sua qualidade de vida. Entretanto, tem sido constante o surgimento de notícias de grupos indígenas que - muitas vezes por terem suas terras invadidas, depredadas e/ou diminuídas - precisam apelar para a invasão de postos da FUNAI (Fundação Nacional do Índio) para o recebimento de medicamentos e, até, mesmo, de cestas básicas de alimentação. Na verdade, são vários os problemas enfrentados pelos povos indígenas, causados por diversos fatores, mas as questões territoriais, de modo especial, estão relacionadas às narrativas nacionais. Muitas vezes, questões como o estabelecimento, a exploração e o direito à terra, afirma Said (1995 apud RAMOS JÚNIOR, 2008), “foram pensadas, discutidas e até, por um tempo, decididas na narrativa”. Assim, diz ele, torna-se muito importante o poder de narrar, ou de impedir que se formem e surjam outras narrativas.

De todo modo, observemos que, enquanto a narrativa nacional brasileira apregoa uma ampla miscigenação entre brancos, negros e índios, a nossa realidade acusa haver uma falta de miscigenação econômica e social. Em vista disto, na atualidade, vários setores sociais têm sido responsabilizados por engendrar uma narrativa que se esmera na divulgação de estereótipos, no fortalecimento ou fixação de preconceitos, e na propagação de uma aculturação que leva os próprios negros e índios a subestimarem-se, negando sua condição racial. Um desses setores é a escola; ela tem contribuído para manter viva a superficialidade da narrativa nacional forjada sobre a questão racial e a miscigenação (GOMES, 2000). Nesse espaço, por um longo período histórico, não se observou o reconhecimento e respeito às particularidades dos modos de ser e de saber do povo negro e dos povos indígenas; e até hoje não é raro que o papel de figurante no cenário de formação do povo brasileiro ainda lhes seja oferecido pela escola.

No cotidiano da sala de aula, são frequentes os relatos de crianças e jovens negros tolhidos no seu desenvolvimento e autoestima por serem feridos na sua dignidade, na comparação de valores e saberes históricos, estéticos, familiares e sociais que tomam como referência a cultura dominante imposta a eles pelos currículos - como viremos a discutir nas próximas seções. Por sua vez, não raro, as culturas indígenas se fazem presentes no currículo de escolas não indígenas como um produto folclórico, como algo do passado e que não diz respeito à atualidade brasileira.

Mas a compreensão de todo ser humano como agente do próprio destino 
e dono de conhecimentos resultantes das experiências de uma vida inteira não pode estar ausente da escola. Configura-se, pois, a importância de nós brasileiros assumirmos nossa identidade marcada pela ação das culturas negras e indígenas, dentre outras, e de fazermos com que as vozes, as culturas e as histórias de minorias se façam ouvir nesse contexto. É por essa razão que a educação escolar tem sido considerada como componente norteador da questão política e racial dos negros e dos índios brasileiros, o que levou à aprovação da Lei 11.645/08.

Essa lei substituiu, complementando, a de número 10.639/03, que alterou a Lei de Diretrizes e Bases da Educação Nacional de 1996 (LDB) incluindo no currículo oficial dos estabelecimentos de ensino básico a obrigatoriedade do estudo da história e cultura afro-brasileira. Com a complementação, tornaram-se também obrigatórias aulas de história e cultura dos povos indígenas. Não se trata de mais uma disciplina no currículo escolar, mas de uma orientação para que todas as disciplinas que constituem o currículo escolar básico - inclusive a matemática - incorporem a discussão acerca da contribuição dos negros e dos índios à cultura brasileira. Desse modo, hoje, a lei impõe aos educadores(as) matemáticos(as) uma tarefa desafiadora, instigando-nos a pesquisar acerca dos conhecimentos matemáticos de origens negras e indígenas de modo a possibilitar-lhes uma abordagem escolar.

A Matemática tem sido uma das principais responsáveis pelas reprovações e evasões no sistema nacional de ensino. Além disso, esta disciplina reproduz, no processo de ensino-aprendizagem, marcas da discriminação e exclusão impostas às minorias sociais pela sociedade. Consideramos que é necessário modificar essa situação; e é nesse sentido que encaminharemos nossas discussões a partir das atuais perspectivas que a Etnomatemática ${ }^{4}$ sugere para a educação escolar que inclua discussões sobre as histórias e os saberes das populações negras e indígenas.

\section{Os compromissos políticos da Etnomatemática no Brasil}

Diferentes concepções, abordagens e enfoques são explorados pelos pesquisadores da Etnomatemática; isso permite que ela não se caracterize exclusivamente

4 D’Ambrosio (2001) explica que o termo "Programa Etnomatemática” refere-se a um programa de pesquisa que busca o conhecimento e a compreensão dos modos de geração, transmissão, institucionalização e difusão desses conhecimentos. Costa (2007) fala em Etnomatemática como sendo um conjunto de conhecimentos, ideias e fazeres que diz respeito à contagem, medição, modelação, inferência, ordenação, localização espacial e temporal de um grupo e que devem ser vistos como indissociáveis de sua linguagem, seus valores, suas práticas sociais, seus mitos, ritos e relações de poder que estabelecem entre si e com outros grupos. 
como um programa de pesquisa, uma postura política ou como uma metodologia de ensino, entre outros (SILVA, 2008). Apesar de enfoques diferenciados, a maioria dos pesquisadores da área fundamenta-se em princípios comuns, entre os quais salientamos: 1) O uso da matemática como instrumento na construção da consciência crítica do indivíduo, tão necessária às lutas pelas transformações sociais; 2) O compromisso e a luta pelo reconhecimento dos valores socioculturais, das técnicas e práticas das minorias étnicas e políticas; 3) O compromisso com a educação transformadora em busca de uma sociedade mais justa. Esses três princípios, dentre outros, afirma Silva (2008), são evidências significativas do envolvimento da Etnomatemática com a luta das minorias políticas representadas pelos grupos étnicos neste país. Eles indicam algumas perspectivas de ação que se inspiram, principalmente, em ideias marxistas, freireanas, socioconstrutivistas e pós-estruturalistas.

Essas perspectivas teóricas, dentre outras, permitem ao pesquisador escolher o enfoque, a concepção teórica e a abordagem que melhor se enquadrem às possibilidades dos trabalhos em desenvolvimento, quer seja no campo da pesquisa acadêmica, na prática docente ou na (re)construção dos currículos escolares. Tal ousadia política da Etnomatemática é que, no Brasil, nos tem permitido realizar pesquisas sobre os saberes matemáticos particulares dos povos negros e indígenas. Na verdade, as práticas, saberes e técnicas de diferentes etnias indígenas vêm sendo foco de pesquisas etnomatemáticas há algumas décadas. Contrariamente, as pesquisas com relação aos povos brasileiros de origem negra se deu recentemente. A quantidade ainda incipiente de trabalhos brasileiros etnomatemáticos sobre cultura negra foi apontada por Costa, Domingues e Jesus (2004), mas, cada vez mais, os pesquisadores que se ocupam de pesquisas junto aos povos de origem negra procuram tornar disponíveis elementos capazes de apoiar políticas e desenvolver estratégias culturais que levem a área de Educação Matemática a contribuir mais efetivamente na constituição de narrativas alternativas, que contribuam para com a descolonização das mentes ${ }^{5}$ no país.

Sob o nosso ponto de vista, os trabalhos desses pesquisadores têm-se estruturado a partir de, pelo menos, três abordagens. Na primeira delas, a busca é por revelar saberes e práticas criados e vivenciados em ambientes predominantemente negros. Assim, em ambiente rural, pesquisas em Etnomatemática têm sido rea-

5 Hall (2002) salienta que o sistema colonial marcou para sempre as sociedades dominadas. Nele, a diversidade era pretexto para a imposição de valores, de costumes culturais, visto que, segundo a sociedade colonial, a diferença constituía como ameaça ao seu crescimento. Essse autor nos assegura também que, apesar da variação em muitos aspectos, de uma a outra parte do globo, os efeitos da colonização se materializam no campo de ação onde, até os dias atuais, convivem e se defrontam os diferentes sujeitos e classes sociais. Daí a necessidade de, na atualidade, nos empenharmos na "descolonização das mentes”, para não estruturamos nossos pensamentos e nossas ações em ideais advindos do colonialismo. 
lizadas junto aos remanescentes de quilombos. Silva (2005) entre outros, é um exemplo das pesquisas que têm trilhado esse caminho. No ambiente urbano, os pesquisadores se concentraram na religiosidade, no futebol, nos bailes de periferias e nas agremiações carnavalescas, como nos mostra Silva (2008). Noutra direção, pesquisadores têm analisado materiais pedagógicos, relações entre professores/ alunos e alunos/alunos. Nessa terceira vertente, a busca por mostrar a existência de saberes matemáticos particulares, de origem negra, por vezes, tem sido acompanhada por propostas de sua utilização na escola e têm sido ressaltadas questões de poder e identidade que fundamentam práticas racistas observadas em ambiente escolar, como em Costa e Silva (2005). Tais abordagens procuram evidenciar diferentes subjetividades e discursos de verdade adotados ao longo da educação brasileira levando à reflexão acerca do que a escola, no âmbito da Educação Matemática, vem dizendo e fazendo com relação aos afro-brasileiros.

Por sua vez, são várias as pesquisas em Etnomatemática sobre culturas indígenas brasileiras ${ }^{6}$. Embora praticamente todas elas procurem identificar e analisar saberes matemáticos indígenas aproximando-se de uma abordagem antropológica, algumas outras vão além disso, propondo ações referentes à formação de professores indígenas ou de agentes de saúde e à produção de material didático para diferentes etnias. É a partir desse panorama mais geral sobre as pesquisas que falaremos sobre as etnomatemáticas negras e indígenas.

\section{A Etnomatemática negra brasileira}

Os antigos africanos escravizados em nosso país, bem como seus descendentes, desenvolveram diferentes tipos de conhecimentos, além de estratégias

6 Dentre as várias pesquisas etnomatemáticas sobre povos indígenas, citamos:

BELLO, S. E. L. Educação Matemática indígena: um estudo etnomatemático com os índios Guarani-Kaiowá do Mato Grosso do Sul. 1995. Dissertação (Mestrado em Educação) - Setor de Educação, Universidade Federal do Paraná/UFPR, Curitiba.

COSTA, W. N. G. A etnomatemática da alma A’uwe-xavante em suas relações com os mitos. 2007, 270p. Tese (Doutorado - Programa de Pós-Graduação em Educação, Área de Concentração: Ensino de Ciências e Matemática) Faculdade de Educação, Universidade de São Paulo, São Paulo, 2008.

RODRIGUES, R. A. As “ticas” de "matema” dos índios Kalapalo: uma interpretação de estudos etnográficos. 2005. Dissertação (Mestrado). UNESP, Rio Claro.

SCANDIUZZI, P.P. Educação indígena X educação escolar indígena: uma relação etnocida em uma pesquisa etnomatemática. 2000. Tese (Doutorado em Educação) —Universidade Estadual Paulista, Marília. 
de resistência e sobrevivência; era o início daquilo que chamamos o modo de saber dos negros brasileiros. Esses conhecimentos foram gerados a partir da diversidade cultural africana, na compreensão/convivência com novas realidades e novos embates políticos e sociais. No interior das senzalas, havia uma convivência entre pessoas de culturas muito diversas, além disso, as fugas rotineiras também reuniam negros de diferentes culturas que se organizavam nos quilombos para resistir à escravatura e à opressão. Nesses encontros, os negros resgataram conhecimentos oriundos de suas várias culturas e, a partir deles, criaram e recriaram conhecimentos. É em decorrência disso que existe no Brasil um tipo de Etnomatemática que é produzida e utilizada pelo próprio corpo negro - dominado, vigiado, mercantilizado pelos europeus-; mas considerado pelos afro-brasileiros como sendo um instrumento de ligação do ser humano com o sagrado, expressão de uma religiosidade que se baseia em mitos ancestrais.

Os mitos são compreendidos como discursos primeiros que estão presentes no interior de todo pensamento teórico. Nascidos a partir de reflexões sobre a criação do mundo, a existência e as situações de estar nele, são discursos que oferecem explicações sobre questões que incomodam os seres humanos. Por sua vez, a ênfase no uso do corpo por parte dos negros intensificou-se pelo fato de que o corpo das pessoas escravizadas encerrava em si toda a herança trazida das tradições africanas. De fato, a diáspora do povo negro para o continente americano teve como elemento de expressão e resistência cultural o corpo, utilizado por meio de expressão de formas simbólicas tais como: a dança, a música, a religiosidade, ou mesmo, a luta, reelaboradas, recriadas em território brasileiro. É a partir dessas raízes mítico/religiosa e corporal que nasce e se renova o conhecimento etnomatemático afro-brasileiro, e, nesse cenário, por exemplo, a roda de capoeira se destaca.

Experiências bem-sucedidas de inclusão e/ou destaque do conhecimento de origem negra nas escolas brasileiras têm se dado com o uso da capoeira, por vezes, a partir de ações interdisciplinares entre professores de Educação Física, de Artes e de Matemática. Essa parceria ressalta pelo menos dois pontos valiosos da cultura negra e, talvez por isso, tenazmente combatidos pela escola até meados do século passado.

No início do século XX, informa-nos Veiga (2000), na formação ética e estética dos educandos brasileiros, havia a preocupação de imprimir uma cultura eurocêntrica, existia a orientação de que ritmos e gostos estéticos de origem negra ou indígena estivessem ausentes do ambiente escolar. Quanto à Educação Física, havia a preocupação em melhorar as condições de vida da população por meio da modificação de hábitos de saúde e higiene. Contudo, como o contingente de negros escravizados era muito grande, políticos e intelectuais brasi- 
leiros também demonstravam uma grande preocupação no sentido de suprimir quaisquer fenômenos que - segundo sua concepção - pudessem favorecer uma visão igualitária entre negros e brancos, levando a uma miscigenação que "desqualificasse" a raça branca (VEIGA, 2000). Daí a impossibilidade de que a capoeira pudesse ser utilizada na escola.

Por essas razões, na atualidade, a inserção da capoeira no ambiente escolar possui uma dimensão simbólica muito maior do que a inicialmente percebida. Significa a valorização dos ritmos negros e da disciplina e agilidade proporcionada pela sua forma de cuidar do corpo e, de certo modo, significa também a valorização do próprio corpo negro. Por sua vez, outro aspecto relevante a ser considerado é o de que a proposta de resgate histórico desses saberes faz aflorar o potencial e a autoestima dos jovens e adolescentes negros. Esses fatores se tornam mais fortes quando considerados no ensino de Matemática, uma das disciplinas mais valorizadas do currículo escolar.

A capoeira de Angola, assim como as suas variações, são lutas de matizes africanas que foram reelaboradas no Brasil pela necessidade de imprimir-lhe um caráter que não permitisse aos senhores de escravos reconhecê-la como um instrumento de resistência. A capoeira se constitui por um intrincado jogo de pernas, braços e movimentos do corpo, limitados por um círculo no chão chamado de roda viva, com projeções no espaço. Nela se observa a ação dos corpos num constante projetar-se num espaço tridimensional desenhando figuras geométricas que se transformam numa sequência rápida à medida que os braços e pernas dos combatentes constroem uma geometria dinâmica. (AUTORES, 2005).

Ao ser disfarçada de dança, a luta ganhou uma cadência chamada ginga que, em síntese, são movimentos de pernas que formam um triângulo imaginário no chão a partir dos quais criam-se várias possibilidades para cada uma das duas posições base (direita e esquerda), de onde todos os golpes são planejados e executados. Impôs-se, dessa forma, não apenas uma negociação do espaço, mas também, do tempo. Então, sob o som do berimbau — um instrumento de percussão com raízes na África, mas típico do Brasil — o corpo se enreda num tempo e espaço que une o novo e o antigo, o sagrado e o profano, num inextricável relacionamento com o conhecimento etnomatemático que vibra e canta no corpo negro.

Para as aulas de Artes, tem sido realizada, a partir da utilização do berimbau, o estudo da influência da cultura negra na música brasileira e, numa parceria com o professor de Matemática, o estudo das escalas musicais. Mas a capoeira tem sido também utilizada de forma eficiente para o ensino de geometria plana e espacial. Sua exploração pedagógica possibilita a aprendizagem de conceitos geométricos (formas geométricas e suas propriedades básicas), percepção espacial, escala e projeção. $\mathrm{O}$ ato de desenhar, no piso da quadra 
da escola, o círculo onde se dá a luta, marca não só o início de estudos sobre a capoeira, mas também sobre o círculo e a circunferência. A marcação de cada pé de apoio trás consigo vértices de trapézios, retângulos e triângulos, riscados com giz no chão. O tempo que se leva estudando os tópicos da geometria plana pode coincidir com o necessário para que os estudantes adquiriram alguma habilidade no jogo, o que lhes será necessário mais adiante. Essa habilidade lhes permitirá perceber a presença dos conceitos da geometria espacial na luta. Mas a utilização da capoeira como recurso pedagógico também alimenta, na aula de Matemática, discussões acerca de valores e da impressão de marcas simbólicas de uma cultura na criação e recriação de conhecimentos matemáticos.

Contudo, nesse cenário, o mais importante é que o(a) professor(a) se assuma como produtor(a) de conhecimentos, como alguém capaz de gerar e/ ou modificar atividades que coloquem em evidência esses e outros saberes de origem negra. Ressaltamos que, ao falar sobre o uso da capoeira nas escolas e, mais adiante, sobre o jogo de búzios, não pretendemos dar nenhuma receita de como trazer para as escolas os saberes negros, pois essas receitas inexistem. $\mathrm{O}$ que existe é uma busca constante, com alguns resultados que mostramos aqui.

Nesse sentido, vale lembrar que o jogo de búzios, como um instrumento da religiosidade de origem negra, também diz respeito a um processo complexo de construção de identidades múltiplas e provisórias, de resistência e adaptação. As religiões de origem negra, ao longo dos anos, foram adaptando-se, deixando ou mudando algumas de suas características com o objetivo de aproximar-se, de certo modo, da religiosidade europeia. Assim, por exemplo, algumas entidades do candomblé ganharam nomes de santos católicos. Mas o jogo de búzios, fundamental para o exercício do candomblé, manteve suas características básicas. Ele é composto por búzios identificados com as divindades mais representativas desta religião. O seu uso se dá a partir de questões pessoais colocadas pelos praticantes do candomblé às entidades - como um oráculo. As respostas são dadas por meio da configuração obtida pelos búzios no momento em que caem lançados de uma pequena altura, isto é, se as suas aberturas, a partir da queda, estão para cima ou para baixo. Desse modo, existe um grande conjunto de diferentes configurações possíveis pelo lançamento dos búzios, que é parte central da resposta à questão colocada.

No espaço escolar, no que se refere ao ensino específico da Matemática, alguns elementos do jogo de búzios podem ser inspiradores no tratamento de tópicos das probabilidades. A proposta não tem sido a de utilizar o jogo propriamente, afinal, ele é um instrumento importante das religiões negras brasileiras, mas sim utilizar alguns de seus princípios no ensino da Matemática. Isso pode se dar quando o(a) professor(a) mostra aos seus alunos que o conjunto de lançamento de búzios segue o modelo probabilístico de Distribuição Binomial (para 
variáveis aleatórias discretas). No jogo, considera-se a hipótese de que cada búzio admite apenas dois resultados (abertura para baixo ou para cima) e que esses resultados são independentes em cada búzio. Combinando as várias repetições do jogo, tem-se, então, um leque de possibilidades de alternativas possíveis, o que nos dá, matematicamente, muitas possibilidades de leitura dos resultados do jogo. Entretanto, no jogo de búzios, também estão presentes, de forma fundante e inextricável, uma componente mítica e outra pessoal e circunstancial - que se referem à interpretação face à situação efetivamente vivida. Esses componentes elevam bastante as possibilidades de leitura da resposta dada e revelam a riqueza e a complexidade da Etnomatemática mítico-religiosa-corporal do negro brasileiro (AUTORES, 2005). Além disso, o trabalho conjunto com professores de Literatura e História torna-se interessante, por permitir analisar as narrativas míticas que fundamentam o jogo e também as narrativas nacionais acerca da religiosidade negra.

Mas não se deve esquecer que o jogo de búzios é um instrumento sagrado, cuja leitura só é permitida aos iniciados. Portanto, ao falarmos dele na escola, ele não pode ser tratado simplesmente como um recurso pedagógico, um jogo matemático. A componente mítico-religiosa do jogo é ressaltada e ele, em si, continuará a ser um mistério, não haverá um real conhecimento de suas regras de leitura; não se pretende, como no uso da capoeira, construir qualquer habilidade do aluno no uso do jogo. Quando trazidos para o ambiente escolar, os búzios não são identificados com entidades e o jogo não diz respeito a problemas pessoais e concretos. A proposta é a de que o jogo de búzios possa ser analisado como uma fonte de problemas probabilísticos e conhecimentos históricos e literários, dentre outros, mas que seja visto e, sobretudo, respeitado como um símbolo da cultura e religiosidade negras.

De todo modo, propostas como a acima citada, que ensejam revelar o saber etnomatemático de origem negra e destacá-lo no contexto escolar, não nos parecem suficientes para abalar a histórica de marginalização do negro nesse espaço. Elas devem ser apoiadas por discussões capazes de ressaltar a existência de relações de poder que têm determinado pensamentos e atitudes na sala de aula e na sociedade em geral, pois, pensamos nós, esta é uma forma de desconstruir narrativas estereotipadas e discriminatórias.

\section{As etnomatemáticas brasileiras de identidades indígenas}

Quando se aborda as culturas indígenas em ambiente escolar não indí- 
gena, tem sido relativamente comum que as marcas das línguas indígenas na composição do vocabulário nacional sejam ressaltadas. O mesmo se dá com relação a alguns hábitos alimentares e ao uso de objetos comuns no cotidiano dos brasileiros. Cada vez mais também têm sido mencionados os conhecimentos indígenas relativos à classificação e uso de plantas e animais e, até mesmo, aqueles que dizem respeito à Etnoastronomia. Entretanto, no que se refere à Matemática, os conhecimentos indígenas ainda tem sido desconsiderados, ou tratados de modo preconceituoso - notadamente quando se trata dos seus processos de contagem. Em vista disto, bem como das razões abaixo expostas, trataremos aqui somente desses processos.

A grande maioria dos grupos humanos conta e, por essa razão, na Matemática, ao se falar sobre criações culturais diferentes, remete-se aos sistemas de contagem. No entanto, ao fazê-lo, rotineiramente, incorre-se no erro de observar prioritariamente a quantidade de termos numéricos utilizados, esquecendo-se de observar que os números não têm as mesmas funções para todos os povos (FERNANDEZ, 2004). Por essa razão, para se falar sobre os saberes matemáticos indígenas em escolas não indígenas, parece-nos que é necessário um maior conhecimento, por parte dos(a) professores(as) de Matemática, dos usos e significados particulares assumidos pelos números pelos diversos povos indígenas. Esse conhecimento poderá debelar os conceitos prévios que tenhamos com relação às suas formas de contagem. Esse será um passo para que, nas aulas de Matemática, não perpetuemos preconceitos com relação a eles. É com esse intuito que trazemos aqui alguns resultados de uma pesquisa realizada junto aos índios A’uwe-xavante do Mato Grosso. Reconhecemos que isso é muito pouco face à diversidade cultural dos povos indígenas brasileiros, mas acreditamos que pode ser um começo.

Autor (2007) afirma que a partir da necessidade de contagem que tinham, os A'uwe-xavante conceberam um número "qualitativo", entendido como regularidade, diferente do número grego (que foi concebido como unidade de medida para um espaço próximo) ou do número ocidental (que preza a infinitude e ganhou a forma de série infinita, curva ou função). Os números $a$ 'uwe-xavante tradicionais evocam o mito de origem desse povo - chamado pelos padres salesianos que primeiro o coletaram de Mito do Arco-íris.

Em síntese, o Mito do Arco-íris diz que existiam dois índios que foram postos na terra por meio do arco-íris (ou originalmente por meio da madeira wamari). Os nomes desses homens foram dados por uma voz que veio do alto (ou da madeira). Essa mesma voz lhes ordenou que tomassem alguns pauzinhos e os pintassem; os pauzinhos se transformaram nas primeiras mulheres xavante e os desenhos nos pauzinhos que as geraram foram considerados símbolos clânicos. Por sua vez, os homens perfuraram suas orelhas colocando os primeiros brincos 
xavante, e depois os primeiros homens e mulheres fizeram preces. Cada um dos casais que se formou teve filhos, dando origem a dois clãs - o dos indivíduos da direita e o dos indivíduos da esquerda; essa foi a origem do povo a'uwe-xavante - dividido em dois clãs.

A contagem tradicional dos A'uwe-xavante se inicia com o termo mitsi (um) que significa "[um pedaço] de lenha-só". A origem da palavra que designa a unidade pode ser associada à madeira wamari, muito provavelmente a voz original que foi posteriormente atribuída ao arco-íris. Assim, o termo que designa o número um, na cultura xavante, lembra o elemento índio que está sozinho, sem o companheiro do outro clã, ou, na atualidade, o rapaz que ainda não ingressou no Hö - a casa dos adolescentes, onde o menino receberá, durante anos, a educação tradicional de seu povo e, também, lhe será designado um parceiro - que é do clã contrário ao seu. $\mathrm{O}$ termo designativo do número dois - maparané - pode ser traduzido como "tem companheiro" e, quando relacionado ao mito e às tradições dos A'uwe-xavante, lembra a existência do companheiro da outra metade clãnica. (AUTOR)

Si'ubdatõ (três) significa que tem um sozinho. Maparané si'uiwanã (quatro) é o dobro de maparané (dois). Por sua vez, imrotõ (cinco) é uma palavra nascida a partir de outras duas imro (esposa) e to (sem) e significa sem esposa; imrõpö (seis) significa o que está junto à esposa. Assim, o número seis marca a possibilidade do começo de um povo ou de uma tribo: dois homens, sendo um de cada clã; duas mulheres, uma de cada clã; e duas crianças, também uma de cada clã (AUTOR 2). Nesse momento, vale ressaltar que, na cultura xavante, uma pessoa de uma metade clânica só se completa com a presença do companheiro do outro clã e que essa composição permite o surgimento de um povo. Desse modo, percebe-se, ao olhar para o sistema binário de contagem desse povo, que os números tradicionais xavante estão intimamente relacionados com o seu mito de origem; seus números possuem um significado diferente do nosso, e que só podemos compreender por meio de um imiscuir-se na sua cultura tradicional e na sua realidade atual.

Notemos ainda que a forma xavante de conceber os números, bem como a sua realidade sócio-histórico-cultural, leva à necessidade de uma pequena sequência de números. A quantidade de itens a serem enumerados pelos índios A’uwe-xavante não é muito grande, visto que o que se enumera são os conjuntos maiores dos quais os objetos fazem parte. A respeito de alguns contextos que poderiam indicar uma sequência maior de números, observemos, por exemplo, que a aldeia, quando começa a ficar grande, é sempre dividida de tal modo que o número de pessoas que a habitam se mantenha relativamente pequeno. Além disso, o apreço pelo acúmulo de bens que não serão efetivamente utilizados não faz parte da cultura indígena não existindo, portanto, essa razão para levar os índios a querer contar números 
grandes. Por outro lado, a relação com o espaço e o sentimento de futuridade também são razões que levam à criação de grandes números. Uma argumentação nesse sentido é apresentada por Autor (2007) levando-nos a perceber, novamente, que, com relação a esses quesitos, os A'uwe-xavante não sentiram necessidade da criação de grandes números, ao contrário do que ocorreu com outros povos. Assim, a pequena quantidade de termos numéricos que usam lhes é adequado, e não há porque olharmos o sistema numérico xavante a partir da quantidade de termos, atribuindo-lhes menor capacidade cognitiva ou matemática. Ao contrário, nosso olhar para seu sistema de contagem deve ser capaz de observar o real significado dos números para esse povo, na imbricação com outros elementos culturais seus e na adequação à sua realidade cotidiana, incluindo aí a vivência mítica.

É importante entendermos também que mesmo quando um povo indígena não possui termos que designem determinado número, isso não significa que os membros da tribo não contem, efetivamente, até chegar a ele. Nesse sentido é elucidativo o trabalho de Silva (2005, p.103,104). Ele ressalta o fato de que, embora tradicionalmente o povo xavante não tenha sentido necessidade de criar nomes para números superiores ao seis, certamente eles realizavam contagens pelo menos até o número quarenta. Os índios narraram ao pesquisador que os velhos faziam marcas de carvão numa árvore - num total de quarenta riscos, para marcar ou confirmar a passagem dos quarenta dias nos quais ritualmente os wapté (adolescentes) batem água para a Festa da Furação de Orelha, na qual após quarenta dias recebem o brinco xavante - que também aparece no mito do Arco-íris.

Desse modo se percebe que, se tradicionalmente os índios xavante só tinham termos até o número seis, isso não significa que sua contagem estivesse limitada a esse número - como muitas vezes se afirma. Isso nos revela que um entendimento maior do seu conhecimento etnomatemático é necessário para compreendermos melhor - e falar para os nossos alunos - sobre essa cultura indígena em nossas escolas.

Ressaltando que no Brasil existem mais de duzentos povos indígenas, torna-se necessário estudarmos mais sobre essas diferentes culturas para, a partir de uma compreensão que vá além de seus sistemas de contagem, colocarmos em prática, no currículo escolar das escolas não indígenas, sugestões como a de Ferreira (1994) para a discussão de saberes indígenas nas aulas de matemática. Ele - após ressaltar que tem sido até certo ponto comum que livros didáticos tragam informações sobre numerações egípcia, babilônia, romana e mesmo maia, mas silenciem quanto à numeração dos povos indígenas brasileiros - sugere que se faça não só discussões sobre os vários sistemas numéricos indígenas, mas também que se pode explorar, por exemplo, a concepção de frações para os Krahó, a importância das diagonais nos retângulos para os Tapirapés e a simetria de rotação na pintura corporal dos Kadawel, dentre outros. 
Pensamos que sugestões como estas propostas por esse hábil pesquisador/ professor de matemática junto a culturas indígenas, permitem-nos, de fato, contribuir para a constituição de uma contranarrativa - que lembre tanto a diversidade cultural dos índios brasileiros, quanto a normalidade de sua capacidade cognitiva e a sua atualidade no cenário brasileiro.

\section{Considerações finais}

A inclusão das culturas e das histórias dos negros e indígenas na escola, isto é, o cumprimento da Lei 11.645/08, dependerá, inclusive, dos lugares político e ideológico que ocuparão os pesquisadores e professores de Educação Matemática. Daí a necessidade de que estes venham a problematizar conceitos prévios e a buscar elementos que os auxiliem na construção de narrativas capazes de abordar as etnomatemáticas desses povos.

Decorre da consciência dessa necessidade o convite que fizemos, por meio desse artigo, para que os professores busquem um maior conhecimento sobre as etnomatemáticas negras e indígenas evidenciando o silenciado, o desconhecido e os mecanismos de dominação e de exploração entre grupos etnoculturais que estão presentes na sociedade brasileira, na escola e, também, no ensino de matemática. Reafirmamos, então, que tal ensino, a ser elaborado a partir da relação entre as diferenças, impõe a necessidade de repensarmos nossas práticas enquanto professores da área, tornando-nos capazes de desestabilizar o olhar que perpetua estereótipos quanto aos saberes matemáticos dos negros e dos índios brasileiros.

\section{REFERÊNCIAS}

AUTOR 1, 2008.

AUTORES 1 E 22005.

AUTOR 22008

BRASIL. Lei n ${ }^{\circ} 11.645$, de 10 março de 2008. Altera a Lei no 9.394, de 20 de dezembro de 1996, modificada pela Lei no 10.639, de 9 de janeiro de 2003, que estabelece as diretrizes e bases da educação nacional, para incluir no currículo oficial da rede de 
ensino a obrigatoriedade da temática "História e Cultura Afro-Brasileira e Indígena". Publicado no DOU de 11.3.2008. Disponível em: <http://www.planalto.gov.br/ ccivil_03/_Ato2007-2010/2008/Lei/L11645.htm>. Acesso em: 16/12/2008.

COSTA, W. N. G.; DOMINGUES, K. C. M.; JESUS, C. L. A Etnomatemática e os estudos afrodescendentes. In: ENCONTRO BRASILEIRO DE ESTUDANTES DE PÓS-GRADUAÇÃO EM EDUCAÇÃO MATEMÁTICA, 9., 2004, Londrina Prioridades de Pesquisa em Educação Matemática: quais os próximos desafios?. Anais... Londrina: UEL, Fundação Araucária, 2004. 1 CD- ROM.

D’AMBROSIO, U. Etnomatemática: elo entre as tradições e a modernidade. Belo Horizonte: Autêntica, 2001.

FERREIRA, E. S. A importância do conhecimento etnomatemático indígena na escola dos não-índios. Em Aberto, v. 14, n. 62, 1994. Disponível em: <http://www.emaberto. inep.gov.br/ index.php/emaberto/issue/view/69>.

HALL, S. Da diáspora: identidades e mediações culturais. Organização: Liv Sovik. Tradução: Adelaine La Guardia Resende et al. Belo Horizonte: Editora UFMG; Brasília: Representação da UNESCO no Brasil, 2003.

RAMOS JÚNIOR, D. V. A disputa por "la costa”: nação, narrativa e identidade na Colômbia (1858-1972). Líber Intellectus, Goiânia, Departamento de História da Universidade Federal de Goiás, ano 2, v. 1, n. 3., 2008. Disponível em: <http://www. liberintellectus.org/artigos.html>.

SILVA, L. M. S. A cerâmica utilitária do povoado histórico Muquém: a Etnomatemática dos remanescentes do Quilombo dos Palmares. Dissertação (Mestrado Profissional em Ensino de Matemática) - Pontifícia Universidade Católica de São Paulo. São Paulo, 2005.

THEODORO, M. et al. (Orgs.). Desigualdades raciais, racismo e políticas públicas 120 anos após a abolição. IPEA, Brasília, 2008. Disponível em: <http://www.ipea. gov.br>.

VEIGA, C. G. Escola de alma branca: o direito biológico à educação no movimento da Escola Nova. Educação em Revista, Belo Horizonte, Faculdade de Educação da UFMG, Número Especial Educação e Relações Étnico-raciais, set. 2000.

Texto recebido em 23 de setembro de 2008.

Texto aprovado em 07 de janeiro de 2009. 